\title{
Prevalence of comorbidities and concomitant medication use in acromegaly: analysis of real-world data from the United States
}

\author{
Maria Fleseriu ${ }^{1}$ (D) Ariel Barkan ${ }^{2} \cdot$ Maria del Pilar Schneider ${ }^{3} \cdot$ Yannis Darhi ${ }^{4} \cdot$ Amicie de Pierrefeu $^{4}$. \\ Antonio Ribeiro-Oliveira Jr. ${ }^{5} \cdot$ Stephan Petersenn ${ }^{6} \cdot$ Sebastian Neggers $^{7} \cdot$ Shlomo Melmed $^{8}$
}

Accepted: 25 November 2021 / Published online: 1 January 2022

(c) The Author(s) 2021

\begin{abstract}
Purpose Patients receiving treatment for acromegaly often experience significant associated comorbidities for which they are prescribed additional medications. We aimed to determine the real-world prevalence of comorbidities and concomitant medications in patients with acromegaly, and to investigate the association between frequency of comorbidities and number of concomitantly prescribed medications.

Methods Administrative claims data were obtained from the IBM® MarketScan ${ }^{\circledR}$ database for a cohort of patients with acromegaly, identified by relevant diagnosis codes and acromegaly treatments, and a matched control cohort of patients without acromegaly from January 2010 through April 2020. Comorbidities were identified based on relevant claims and assessed for both cohorts.

Results Overall, 1175 patients with acromegaly and 5875 matched patients without acromegaly were included. Patients with acromegaly had significantly more comorbidities and were prescribed concomitant medications more so than patients without acromegaly. In the acromegaly and control cohorts, respectively, $67.6 \%$ and $48.4 \%$ of patients had cardiovascular disorders, the most prevalent comorbidities, and $89.0 \%$ and $68.3 \%$ were prescribed $>3$ concomitant medications $(\mathrm{p}<0.0001)$. Hypopituitarism and hypothalamic disorders, sleep apnea, malignant neoplasms and cancer, and arthritis and musculoskeletal disorders were also highly prevalent in the acromegaly cohort. A moderate, positive correlation (Spearman correlation coefficient 0.60 ) was found between number of comorbidities and number of concomitant medications in the acromegaly cohort. Conclusion Compared with patients without acromegaly, patients with acromegaly have significantly more comorbidities and are prescribed significantly more concomitant medications. Physicians should consider the number and type of ongoing medications for individual patients before prescribing additional acromegaly treatments.
\end{abstract}

Keywords Acromegaly $\cdot$ Comorbidities $\cdot$ Concomitant medications $\cdot$ Injectable medications $\cdot$ Oral medications $\cdot$ Realworld data

Maria Fleseriu

fleseriu@ohsu.edu

1 Pituitary Center, Division of Endocrinology, Diabetes and Clinical Nutrition, Departments of Medicine and Neurological Surgery, Oregon Health \& Science University, 3303 SW Bond Ave, Mail Code CH8N, Portland, OR 97239, USA

2 A. Alfred Taubman Health Care Center, University of Michigan, Ann Arbor, MI, USA

3 Ipsen, Les Ulis, France
Ipsen, Boulogne-Billancourt, France

5 Ipsen, Cambridge, MA, USA

6 ENDOC Center for Endocrine Tumors, Erik-Blumenfeld-Platz 27a, 22587 Hamburg, Germany

7 Department of Medicine, Section Endocrinology, Pituitary Center Rotterdam, Erasmus University Medical Center Rotterdam, Rotterdam, The Netherlands

8 Cedars-Sinai Medical Center, Los Angeles, CA, USA 


\section{Introduction}

Acromegaly is generally caused by a growth hormone (GH)secreting pituitary adenoma, resulting in GH excess and elevated insulin-like growth factor 1 (IGF-1) levels [1-3]. Clinical manifestations of the disease are driven by prolonged GH or IGF-1 exposure, as well as by local tumor compressive effects [4-7]. Typical symptoms of acromegaly include physical manifestations, including enlargement of hands and feet and coarsening of the facial features, as well as arthritis, diabetes, hypertension, and sleep apnea $[4,8,9]$. Excess GH and/or IGF-1 levels also cause metabolic dysfunction and cardiovascular and musculoskeletal comorbidities; these can lead to cardiovascular and respiratory abnormalities and decreased quality of life [4,10-14]. There is an approximately two-fold excess in mortality in patients with uncontrolled acromegaly compared with the general population $[2,15,16]$, as well as an increased cost associated with comorbidity treatment and reduced quality of life [17].

Acromegaly can be treated with surgery, pharmacotherapy [somatostatin receptor ligands (SRLs), GH receptor antagonists, dopamine agonists, or combinations of the above], and/or radiotherapy [2, 18]. In addition to therapies targeting GH and IGF-1 oversecretion, patients often require treatment for acromegaly-related comorbidities, resulting in prescription of multiple medications [19]. Pharmacotherapy treatments for acromegaly and associated comorbidities are administered as oral medications, subcutaneous (SC) injections, and intramuscular (IM) injections [20]. Prescription of multiple medications has been linked with poor adherence and low patient satisfaction and quality of life, especially in patients with chronic illness or more than one comorbidity [21-25], as well as an increased risk of adverse events related to drug-drug interactions [26, 27]. Furthermore, different routes of medication administration are associated with respective advantages and disadvantages related to ease of administration, medication absorption, and reactions with other medications $[28,29]$. Taking all these factors into account, it is important for physicians to consider the quantity and form of medications a patient is already receiving when prescribing additional treatments.

Real-world evidence on the frequency of comorbidities and the associated prevalence of prescribed concomitant medications in patients with acromegaly is limited. Accordingly, we determined the prevalence of comorbidities and concomitant medications in a real-world population of patients with acromegaly, as well as in a control cohort of patients without acromegaly, using administrative claims data from the United States (US). Additionally, an analysis of the sub-group of patients with acromegaly receiving prolonged anticoagulant treatment assessed the use of injectable medications in these patients. The sub-analysis was of interest due to the potential risk of bleeding and bruising associated with use of IM injectable medications in conjunction with anticoagulants. This study also sought to evaluate any association between frequency of comorbidities and number of concomitantly prescribed medications in the population of patients receiving anticoagulants.

\section{Methods}

\section{Study design}

This analysis presents results from a real-world, retrospective cohort study of administrative claims data obtained from the IBM ${ }^{\circledR}$ MarketScan ${ }^{\circledR}$ claims database in the US from January 2010 through April 2020. The database is compliant with the US Health Insurance Portability and Accountability Act of 1996 (HIPAA), with all patient-level data deidentified. MarketScan covers resource use and cost data for inpatient and outpatient services, with claims from patients with multiple insurance types throughout the US. Information is derived from medical claims linked to inpatient treatment, outpatient prescription drug claims, and person-level enrollment data.

Claims associated with medical diagnoses and treatment prescriptions were extracted for eligible patients. Comorbidities included in the analysis were selected by referring to published consensus statements and in consultation with the co-authors to reflect acromegaly-related comorbidities seen in clinical practice [15]. An occurrence of a comorbidity was defined by at least one relevant claim. Additionally, the Charlson Comorbidity Index (CCI), a method of categorizing comorbidities based on International Classifications of Diseases (ICD) codes, was calculated for patients with and without acromegaly [30]. In the methodology described by Quan et al. [30], each of 17 pre-specified comorbidity categories have an associated weight based on the adjusted risk of mortality or resource use; the sum of all relevant weights results in a single CCI score for a patient. The use of concomitant medications was defined by at least one relevant claim and the medications were analyzed using the Anatomical Therapeutic Chemical Classification as well as by active ingredient. A sub-analysis of patients with acromegaly receiving prolonged anticoagulant treatment was conducted to investigate the use of injectable medications in these individuals (defined by at least one relevant claim for an injectable medication).

\section{Patients}

A cohort of patients with acromegaly and a control cohort of patients without acromegaly were extracted from the MarketScan database. Patients were eligible for inclusion in the 
acromegaly cohort if they had: at least two claims associated with any ICD, 9th Revision, Clinical Modification (ICD9-CM) or ICD, 10th Revision, Clinical Modification (ICD10-CM) diagnosis codes for acromegaly (E22.0 or 253.0), with more than 30 days between the first and second claim; received at least one treatment for acromegaly with specific treatments including lanreotide depot, octreotide long-acting release (LAR), pasireotide, cabergoline, bromocriptine, and pegvisomant; and had at least 3 months of claims data before the earlier date of either the claim for first diagnosis or the claim for first treatment. Inclusion criteria were selected to ensure that patients had a definite diagnosis of acromegaly, and that the data captured the correct treatment start date, to avoid data bias. As one of the main focuses of this analysis was the use of concomitant medications in patients who were actively receiving medical therapy to treat acromegaly, patients who were not receiving medical therapy (such as those in remission due to surgery and/or radiation) were not included. All patients who met the eligibility criteria for acromegaly using data from MarketScan were included in the study.

Patients were eligible for inclusion in the control cohort if they had no medical claims related to acromegaly, although it was possible for patients in the control cohort to have records for other underlying conditions. A random sample (10\%) of patients in the MarketScan database with no medical claims for any ICD-9-CM or ICD-10-CM diagnosis codes for acromegaly (E22.0 or 253.0) within the study period were selected as the initial pool of patients in the control cohort. Direct matching 1:5 (patients with acromegaly to patients without acromegaly) was performed based on age and sex. The observation period (first record date to last record date) of each patient in the control cohort had to include the study period (from the first treatment date to the last record date) of the matched patient with acromegaly. The index date (the date on which the patient fulfilled the eligibility criteria) of each patient in the control cohort was the same as the index date of their matched patient with acromegaly, and in both cohorts, patients had at least 3 months of data prior to the index date.

Patients receiving anticoagulant medications were eligible for inclusion in the anticoagulation sub-analysis if they received an anticoagulant medication (specifically: warfarin, enoxaparin, apixaban, rivaroxaban, fondaparinux, dalteparin, heparin, or dabigatran) daily for $>45$ days (to avoid including patients on prophylactic doses of anticoagulants) and had at least one record for an injectable medication (including intravenous [IV], SC, and IM) between the first and last records of an anticoagulant medication. The subanalysis included four cohorts: patients in the acromegaly cohort receiving anticoagulants; patients in the acromegaly cohort not receiving anticoagulants; patients in the control cohort receiving anticoagulants; and patients in the control cohort not receiving anticoagulants.

\section{Study outcomes}

Outcomes evaluated for the acromegaly and control cohorts included: prevalence of acromegaly-related comorbidities (cardiovascular disorders, arthritis and musculoskeletal disorders, malignant neoplasms and cancer, type 2 diabetes mellitus, sleep apnea, hypopituitarism and disorder of hypothalamus, and bone disorders); the CCI score for each cohort; prevalence and type of prescribed concomitant medications; percentage of patients with each comorbidity receiving $0,1,2-3$, and $>3$ concomitant medications; and correlation between number of comorbidities and number of concomitant medications. Additionally, within the subset of patients who were receiving anticoagulants, the prevalence of comorbidities and prescribed injectable concomitant medications was analyzed.

\section{Statistical analysis}

Demographic characteristics were analyzed using descriptive statistics, with continuous variables presented as the mean and standard deviation (SD), and categorical or discrete variables presented as percentages. Python language was used for data preparation and statistical analyses [31]. Chi-squared tests were used for inter-cohort proportional comparisons and mean CCI score was compared between the acromegaly and control cohorts using an unpaired t-test. An unpaired t-test was also used to compare the average count of different active medication ingredients between the acromegaly and control cohorts. Medications containing multiple active ingredients were analyzed by individual ingredient. Spearman correlation coefficients and p-values were calculated between the number of different concomitant medications and the number of different comorbidities. For all analyses, a p-value of $<0.05$ was considered statistically significant.

\section{Results}

\section{Patient disposition and baseline characteristics}

The acromegaly cohort included 1175 patients, while the matched control cohort included 5875 patients; in both cohorts, $50.1 \%$ of patients were female and mean (SD) age was 48.5 (14.0) years. Complete demographics and baseline characteristics are presented in Table 1. A total of 52 patients were included in the sub-cohort of patients with acromegaly receiving anticoagulants; 1123 patients were included in the sub-cohort of patients with acromegaly not 
Table 1 Demographics and baseline characteristics in the acromegaly and control cohorts

\begin{tabular}{lll}
\hline & $\begin{array}{l}\text { Acromegaly cohort } \\
(\mathrm{N}=1175)\end{array}$ & $\begin{array}{l}\text { Control cohort } \\
(\mathrm{N}=5875)\end{array}$ \\
\hline $\begin{array}{l}\text { Sex, } \mathrm{n}(\%) \\
\quad \text { Male }\end{array}$ & $586(49.9)$ & $2930(49.9)$ \\
$\quad$ Female & $589(50.1)$ & $2945(50.1)$ \\
Age & & \\
$\quad \begin{array}{l}\text { Mean (SD) } \\
\text { Median (95\% CI) }\end{array}$ & $58.5(14.0)$ & $48.5(14.0)$ \\
Study period (index date to & & $50.0(49.0-51.0)$ \\
$\quad$ end of data) (years) & & \\
$\quad \begin{array}{l}\text { Mean (SD) } \\
\text { Median (95\% CI) }\end{array}$ & $2.8(2.4)$ & $2.8(2.4)$ \\
\hline
\end{tabular}

$C I$ confidence interval, $S D$ standard deviation

receiving anticoagulants; 131 patients without acromegaly were included in the control cohort of patients receiving anticoagulants; and 5744 patients without acromegaly were included in the control cohort of patients not receiving anticoagulants. Complete demographics and baseline characteristics for the anticoagulation sub-analysis are presented in Table 2.

\section{Prevalence of comorbidities}

Cardiovascular disorders were the most prevalent comorbidity category observed across both the acromegaly and control cohorts, experienced by $67.6 \%$ and $48.4 \%$ of patients, respectively. In the acromegaly versus the control cohort, there was also a higher prevalence of hypopituitarism and disorders of hypothalamus ( $26.3 \%$ vs. $0.2 \%$ ), sleep apnea ( $24.9 \%$ vs. $7.8 \%)$, malignant neoplasms and cancer $(22.6 \%$ vs. $8.6 \%$ ), and arthritis and musculoskeletal disorders (19.9\% vs. $12.9 \%$, respectively; Fig. 1). Compared with patients in the control cohort, a significantly higher percentage of patients in the acromegaly cohort experienced each comorbidity category (each $\mathrm{p}<0.05$ ). Similarly, the mean
CCI score was significantly higher in the acromegaly cohort (1.4) than in the control cohort $(0.58 ; \mathrm{p}<0.0001$; Table 3$)$.

In the sub-analysis of patients receiving prolonged anticoagulant treatment, cardiovascular disorders were the most prevalent comorbidities in all cohorts, reported in $98.1 \%, 66.6 \%, 93.9 \%$, and $46.6 \%$ of patients with acromegaly receiving anticoagulants, patients with acromegaly not receiving anticoagulants, patients in the control cohort receiving anticoagulants, and patients in the control cohort not receiving anticoagulants, respectively. Patients with acromegaly receiving anticoagulants had a significantly higher prevalence of type 2 diabetes mellitus and glucose intolerance and malignant neoplastic disease than all three comparison cohorts (diabetes: $48.1 \%$ vs. $19.1 \%, 29.0 \%$, and $8.1 \%$ of patients, respectively; malignant neoplastic disease: $48.1 \%$ vs. $21.6 \%, 0.0 \%$, and $0.0 \%$ of patients, respectively) and experienced a significantly higher prevalence of all comorbidities when compared with the cohort of patients without acromegaly not receiving anticoagulants $(\mathrm{p}<0.05$; Table 4).

\section{Prescription of concomitant medications}

A significantly higher percentage of patients in the acromegaly cohort than in the control cohort were prescribed each class of concomitant medication (each $\mathrm{p}<0.05$; Supplementary Table 1). The most prevalent class of concomitant medications for both cohorts was antibacterials for systemic use ( $70.0 \%$ vs. $55.6 \%$, respectively), followed by analgesics (56.3\% vs. $38.1 \%)$ and cough and cold preparations $(46.4 \%$ vs. $35.5 \%)$. A high percentage of the acromegaly cohort were additionally prescribed psycholeptics $(42.6 \%)$ and sex hormones and modulators of the genital system (37.3\%); these medication classes were less prevalent in the control cohort, prescribed to $24.8 \%$ and $12.7 \%$ of patients, respectively (Fig. 2).

Most concomitant medications were taken in oral form $(67.9 \%), 15.1 \%$ were taken as injectables, and $17.0 \%$ were taken in a form other than oral or injectable. The analysis found that regardless of route of administration, all

Table 2 Demographic characteristics for the sub-analysis of patients with acromegaly receiving anticoagulants

\begin{tabular}{|c|c|c|c|c|}
\hline & \multirow{2}{*}{$\begin{array}{l}\text { Case cohort } \\
\text { Patients with acromegaly } \\
\text { receiving anticoagulants } \\
(\mathrm{N}=52)\end{array}$} & \multicolumn{3}{|l|}{ Comparison groups } \\
\hline & & $\begin{array}{l}\text { Patients with acromegaly } \\
\text { not receiving anticoagulants } \\
(\mathrm{N}=1123)\end{array}$ & $\begin{array}{l}\text { Patients without acromegaly } \\
\text { receiving anticoagulants } \\
(\mathrm{N}=131)\end{array}$ & $\begin{array}{l}\text { Patients without acromegaly } \\
\text { not receiving anticoagulants } \\
(\mathrm{N}=5744)\end{array}$ \\
\hline \multicolumn{5}{|l|}{ Sex, n (\%) } \\
\hline Male & $33(63.5)$ & $553(49.2)$ & $71(54.2)$ & $2859(49.8)$ \\
\hline Female & $19(36.5)$ & $570(50.8)$ & $60(45.8)$ & $2885(50.2)$ \\
\hline \multicolumn{5}{|l|}{ Age } \\
\hline Mean (years) & 60.4 & 47.8 & 62.0 & 48.2 \\
\hline
\end{tabular}




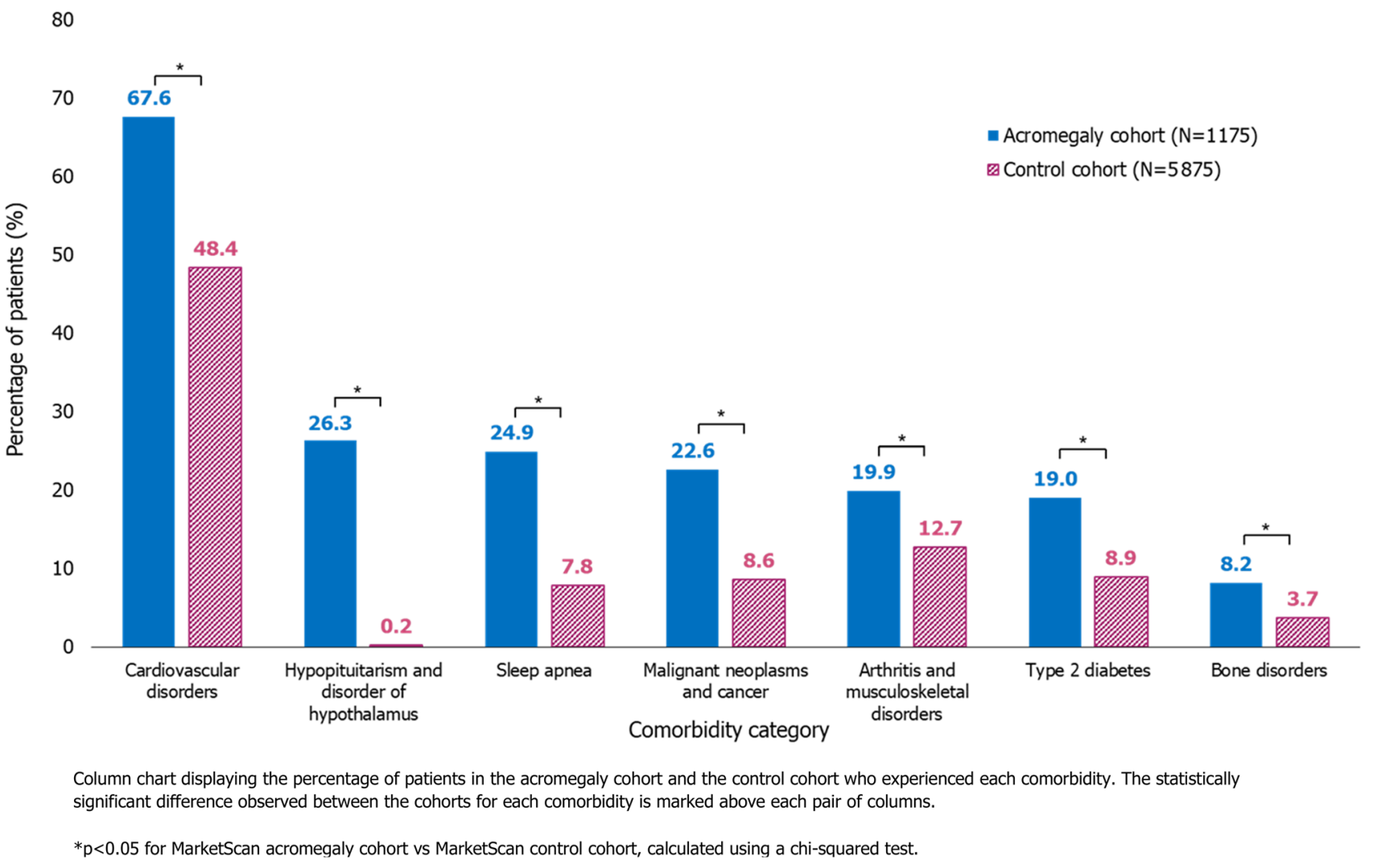

Fig. 1 Prevalence of comorbidities in the acromegaly and control cohorts

Table 3 Charlson comorbidity index of patients in the acromegaly and control cohorts

\begin{tabular}{lll}
\hline & $\begin{array}{l}\text { Acromegaly cohort } \\
(\mathrm{N}=1175)\end{array}$ & $\begin{array}{l}\text { Control } \\
\text { cohort } \\
(\mathrm{N}=5875)\end{array}$ \\
\hline $\mathrm{CCI}$ & & \\
Mean* & 1.4 & 0.58 \\
Median & 1.0 & 0.0 \\
SD & 2.1 & 1.3 \\
$95 \% \mathrm{CI}$ & $(1.2-1.5)$ & $(0.55-0.62)$ \\
\hline
\end{tabular}

$C C I$ Charlson Comorbidity Index, $C I$ confidence interval, $S D$ standard deviation

*p-value $<0.0001$ for acromegaly cohort vs. control cohort, calculated using an unpaired t-test

concomitant medication ingredients except for lisinopril (an oral medication) were prescribed to significantly more patients in the acromegaly cohort than the control cohort $(\mathrm{p}<0.05$; Supplementary Table 2).

For patients receiving anticoagulants, a significantly higher percentage of patients with acromegaly were prescribed concomitant injectable medications compared with those without acromegaly ( $88.5 \%$ vs. $67.9 \%$; $=0.0078)$. The injectable medication ingredients most frequently prescribed to patients with acromegaly who were receiving anticoagulants were: IV sodium chloride (32.7\% of patients), IM/IV midazolam (32.7\%), IM octreotide LAR (26.9\%), IV ondansetron (26.9\%), SC lanreotide depot (25.0\%), and IM/ IV cefazolin (21.2\%; Fig. 3).

\section{Number of prescribed concomitant medication ingredients by comorbidity}

Across the acromegaly and control cohorts, respectively, $2.5 \%$ and $15.0 \%$ of patients were prescribed 0 concomitant medication ingredients $(\mathrm{p}<0.0001), 3.1 \%$ and $5.4 \%$ were prescribed $1(\mathrm{p}=0.0014), 5.4 \%$ and $11.3 \%$ were prescribed $2-3(\mathrm{p}<0.0001)$, and $89.0 \%$ and $68.3 \%$ were prescribed $>3$ $(\mathrm{p}<0.0001)$, accounting for medications taken via all routes of administration (oral, injectable, and neither oral nor injectable).

Usage of concomitant medications in patients with comorbidities was high, regardless of acromegaly diagnosis, with more than $85 \%$ of patients being prescribed $>3$ concomitant medication ingredients (Fig. 4). When analyzed by route of administration, this high concomitant usage was driven by oral medications more than injectable medications (Supplementary Table 3). For any given comorbidity, over 
Table 4 Prevalence of comorbidities in all cohorts of the anticoagulation sub-analysis

\begin{tabular}{|c|c|c|c|c|}
\hline & $\begin{array}{l}\text { Patients with acromegaly } \\
\text { receiving anticoagulants } \\
(\mathrm{N}=52)\end{array}$ & $\begin{array}{l}\text { Patients with acromegaly } \\
\text { not receiving anticoagu- } \\
\text { lants }(\mathrm{N}=1123)\end{array}$ & $\begin{array}{l}\text { Patients without acromeg- } \\
\text { aly receiving anticoagu- } \\
\text { lants }(\mathrm{N}=131)\end{array}$ & $\begin{array}{l}\text { Patients without acromegaly } \\
\text { not receiving anticoagulants } \\
(\mathrm{N}=5744)\end{array}$ \\
\hline \multicolumn{5}{|l|}{ Comorbidity, n (\%) } \\
\hline Cardiovascular disorders & $51(98.1)$ & $748(66.6)^{*}$ & $123(93.9)$ & $2676(46.6)^{*}$ \\
\hline $\begin{array}{l}\text { Malignant neoplasms and } \\
\text { cancer }\end{array}$ & $25(48.1)$ & $243(21.6)^{*}$ & $0(0.0)^{*}$ & $2(0.03)^{*}$ \\
\hline $\begin{array}{l}\text { Type } 2 \text { diabetes mellitus } \\
\text { and glucose intolerance }\end{array}$ & $25(48.1)$ & $215(19.1)^{*}$ & $38(29.0)^{*}$ & $466(8.1)^{*}$ \\
\hline Sleep apnea & $20(38.5)$ & $274(24.4)^{*}$ & $39(29.8)$ & $387(6.7)^{*}$ \\
\hline $\begin{array}{l}\text { Hypopituitarism and disor- } \\
\text { der of hypothalamus }\end{array}$ & $15(28.8)$ & $297(26.4)$ & $0(0.0)^{*}$ & $8(0.14)^{*}$ \\
\hline $\begin{array}{l}\text { Arthritis and musculoskel- } \\
\text { etal disorders }\end{array}$ & $15(28.8)$ & $225(20.0)$ & $34(26.0)$ & $697(12.1)^{*}$ \\
\hline Bone disorders & $6(11.5)$ & $90(8.0)$ & $18(13.7)$ & $166(2.8)^{*}$ \\
\hline
\end{tabular}

$* \mathrm{p}<0.05$ for comparison with the cohort of patients with acromegaly receiving anticoagulants, calculated using a chi-squared test

$80 \%$ of patients were prescribed $>3$ oral medications; for injectable medications this was fewer than $52 \%$ of patients.

\section{Correlation analysis}

Moderate positive associations were found between the number of comorbidities and number of all concomitant medications (including medications of all reported routes of administration; oral, injectable, and neither oral nor injectable) and oral concomitant medications, indicated by Spearman correlation coefficients of 0.60 and 0.59 , respectively (both $\mathrm{p}<0.001$; Fig. 5). Conversely, low positive correlations were reported between number of comorbidities and number of injectable and neither oral nor injectable concomitant medications, as indicated by a Spearman correlation coefficient of 0.45 for each (both $\mathrm{p}<0.001$ ).

\section{Discussion}

In this real-world, controlled analysis, patients with acromegaly had a higher frequency of acromegaly-related comorbidities and were prescribed more concomitant medications compared with patients without acromegaly. The prevalence of comorbidities in our study generally aligned with the incidence rates of comorbidities previously reported. In a real-world study in the US assessing 23 acromegalyrelated comorbidities, high incidence rates for arthropathy, arthralgia, synovitis, hypertension, hypopituitarism, osteoarthritis, and diabetes were reported [19]. An observational study showed that the most prevalent comorbidities were endocrine and metabolic diseases, including diabetes, bone diseases, and hypopituitarism (96.7\%); cardiovascular diseases (70.7\%); and musculoskeletal disorders (22.0\%) [32].
Similarly, a large study using the Liege Acromegaly Survey Database reported high rates of metabolic disorders (such as diabetes), cardiovascular disorders, and thyroid disorders in patients with acromegaly [33]. As expected, each acromegaly-related comorbidity observed in our study was experienced by significantly more patients with acromegaly compared with the control cohort. For instance, the proportion of patients with cerebrovascular disorders (within the cardiovascular disorders category) in the acromegaly cohort was nearly twice that of the matched control cohort. Additionally, the significantly higher CCI score for patients with acromegaly calculated in our analysis demonstrates a broad comorbidity presence. While the CCI has not been validated for acromegaly specifically, it provides a valuable, quantified measurement for comparison between the acromegaly and control cohorts. While it would have been interesting to explore the interaction between different comorbidities in the anticoagulation sub-analysis, the descriptive nature of the analysis and the small number of patients with acromegaly receiving anticoagulants precluded the feasibility of conducting a multivariate analysis.

The high prevalence of comorbidities in patients with acromegaly was reflected in the observed frequency of prescribed concomitant medications. For example, $19.0 \%$ of patients in the acromegaly cohort had a diagnosis of diabetes and $24.4 \%$ of patients were receiving diabetes medications. The correlation analysis further suggested a link between comorbidities and concomitant medication usage, with a moderate, positive association found between the number of comorbidities and the number of all and oral concomitant medications. This result confirms that patients with acromegaly experience an increased frequency of acromegaly-related comorbidities, which may in turn require a greater number of concomitant medications. Among the 


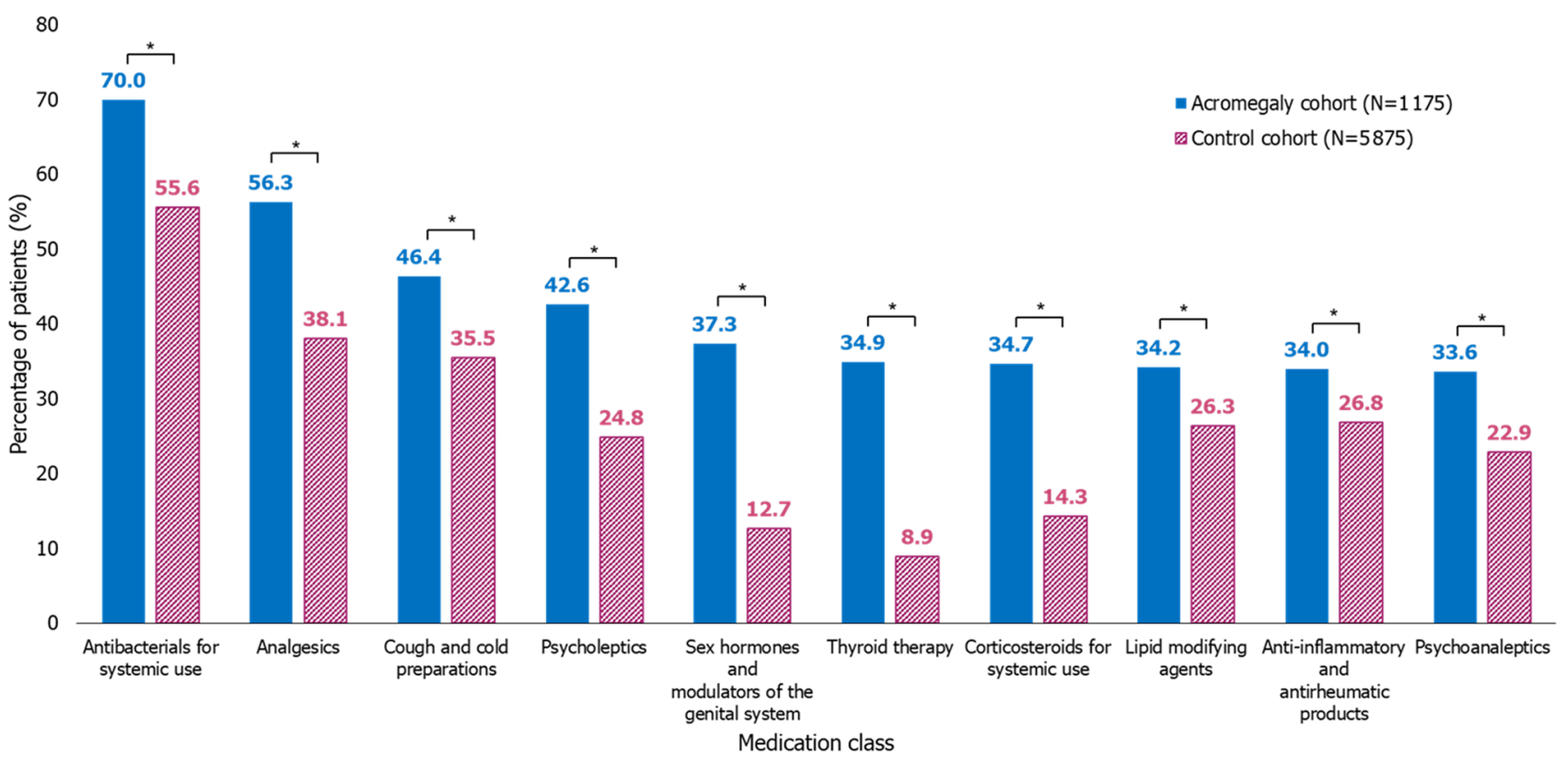

Column chart displaying the percentage of patients in the acromegaly cohort and the control cohort who were prescribed the ten most prevalent concomitant medications in the acromegaly cohort. The statistically significant difference observed between the cohorts for each medication is marked above each pair of columns.

${ }^{*} \mathrm{p}<0.05$ for MarketScan acromegaly cohort vs MarketScan control cohort, calculated using a chi-squared test.

Fig. 2 Prevalence of concomitant medications by Anatomical Therapeutic Chemical Classification in the acromegaly and control cohorts

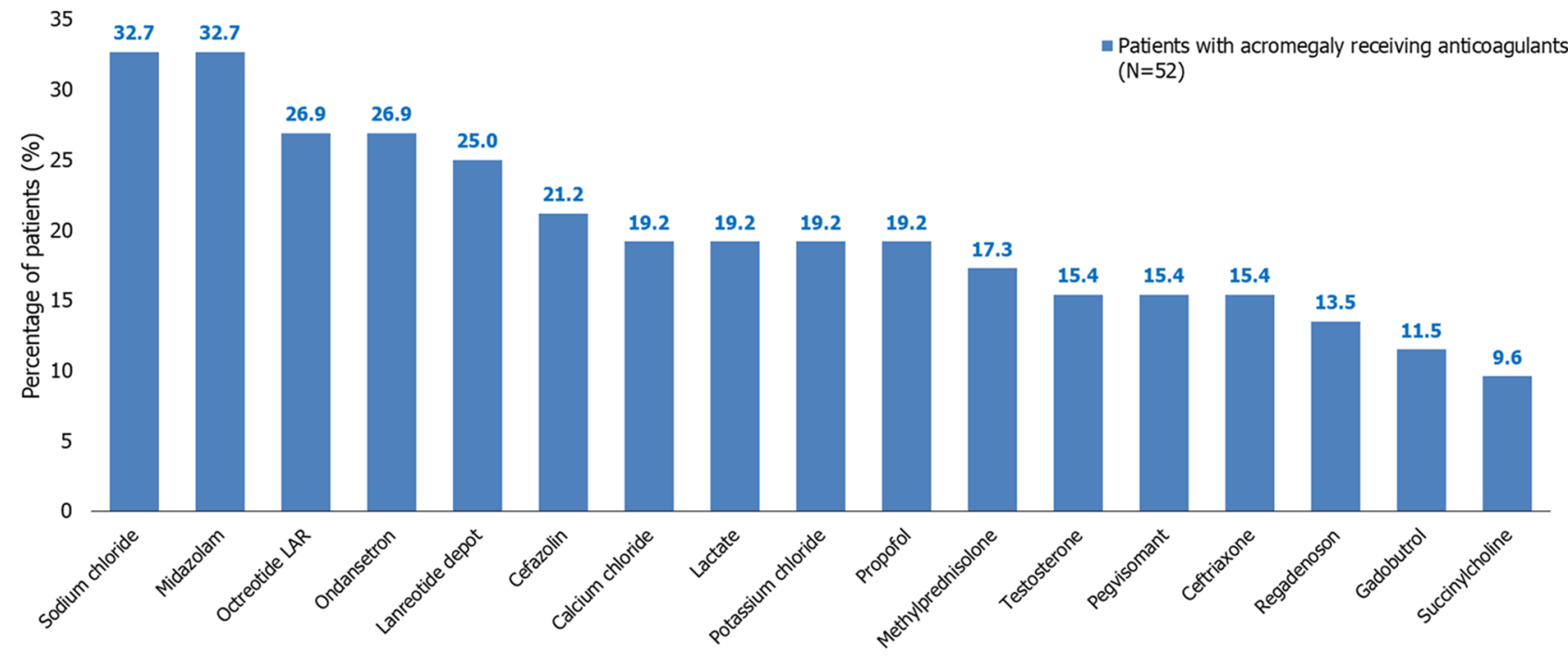

Injectable medication ingredient

Column chart displaying the percentage of patients in the cohort of patients with acromegaly receiving anticoagulants who were prescribed each injectable concomitant medication ingredient.

Fig. 3 Injectable medications by ingredient in the cohort of patients with acromegaly receiving anticoagulants

concomitant medications prescribed to a significantly greater number of patients with acromegaly were psychotropic and pain medications, underscoring the unmet need for a focus on mental health and pain management required for patients with acromegaly.

In aggregate, we report significantly higher concomitant medication use in patients with acromegaly than in patients 

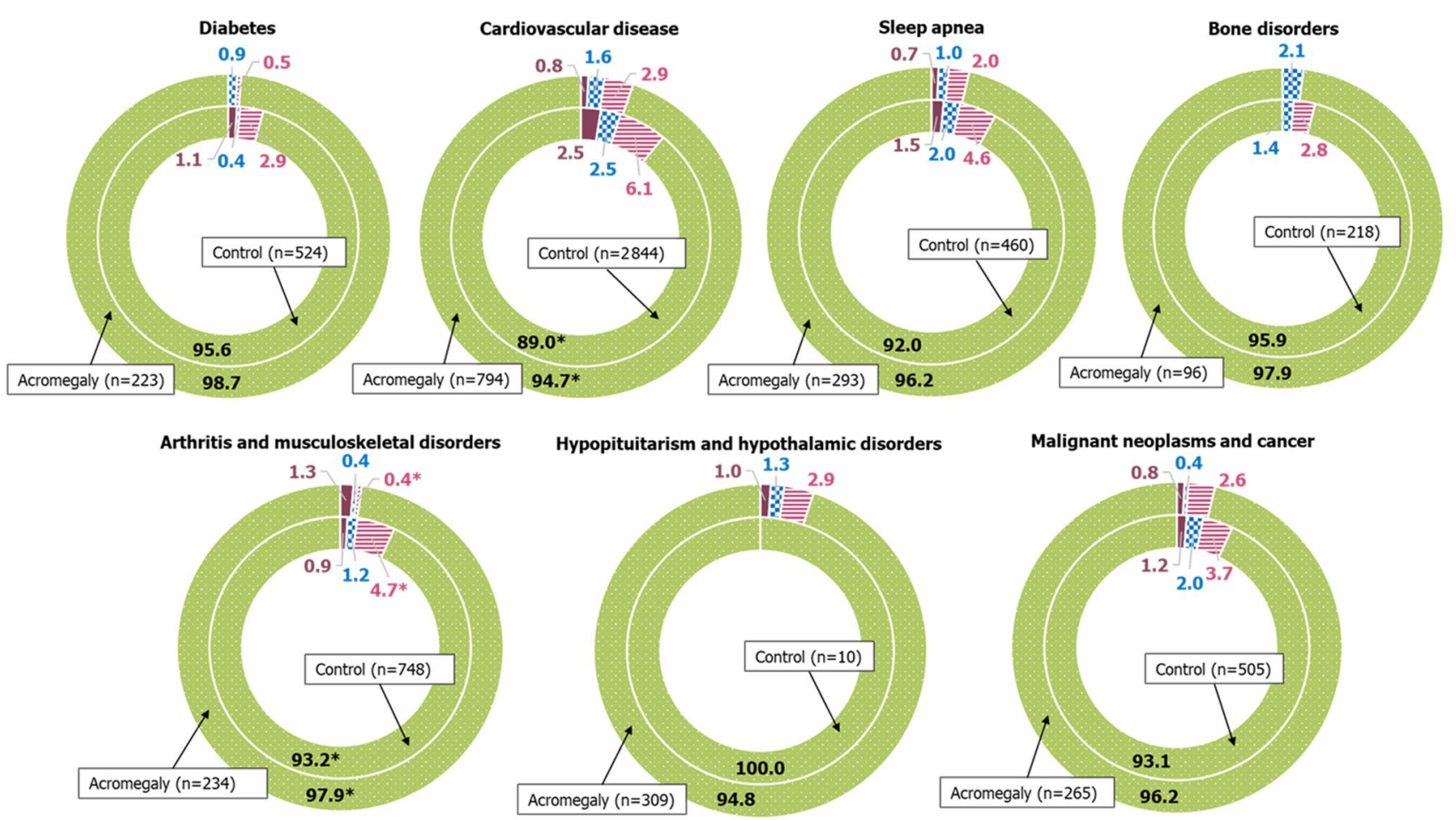

0 Ingredients 81 Ingredient $\equiv 2-3$ Ingredients $>3$ Ingredients

A series of pie charts (one for each comorbidity) which display the percentage of patients in the acromegaly and control cohorts experiencing each comorbidity who were prescribed $0,1,2-3$, and $>3$ concomitant medication ingredients. n numbers represent the number of patients in each cohort who experienced each specific comorbidity. ${ }^{*} \mathrm{p}<0.05$ for comparison of number of medication ingredients between MarketScan acromegaly cohort and MarketScan control cohort, calculated using an unpaired $\mathrm{t}$-test.

Fig. 4 Percentage of prescribed concomitant medication ingredients by comorbidity in the acromegaly and control cohorts

(a) All concomitant medications

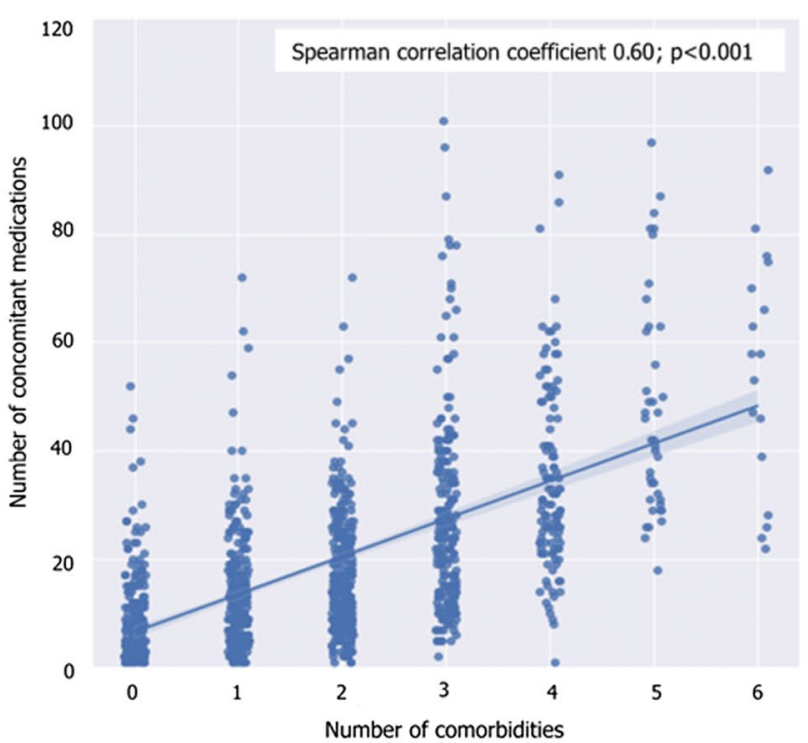

\section{(b) Oral concomitant medications}

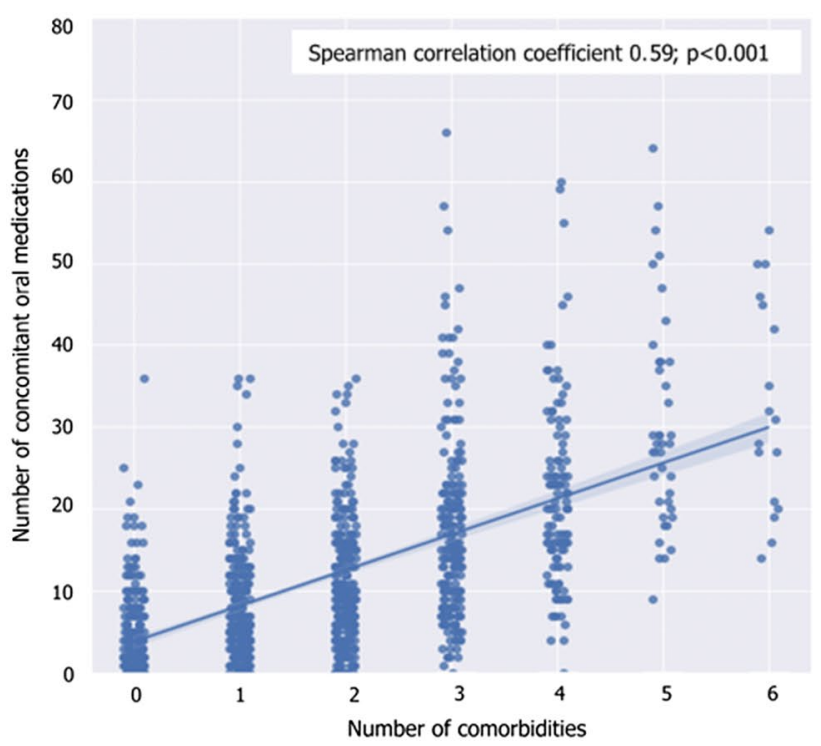

Scatterplots displaying the relationship between a) number of comorbidities and number of all concomitant medications, and b) number of comorbidities and number of concomitant oral medications, based on Spearman correlation coefficients.

Fig. 5 Correlation between number of comorbidities and number of prescribed concomitant medications in the acromegaly cohort 
without acromegaly $(89.0 \%$ and $68.3 \%$ of the acromegaly and control cohorts, respectively, received $>3$ concomitant medications). However, in both the acromegaly and control cohorts, most patients with comorbidities were prescribed $>3$ concomitant medications. This finding confirms our expectation that increased concomitant medication usage is driven by comorbidities. Due to the higher overall prevalence of comorbidities in patients with acromegaly, these patients are also prescribed more concomitant medications. A prior study reported that approximately $60 \%$ of all adults in the US were prescribed $\geq 1$ medication, with $15 \%$ reporting the use of $\geq 5$ prescription medications [34]. In our study, $97.5 \%$ of patients with and $85.0 \%$ of patients without acromegaly were prescribed $\geq 1$ medication; conversely, only $2.5 \%$ of patients with acromegaly were prescribed 0 concomitant medications, versus $15.0 \%$ of patients without acromegaly. These results suggest that while patients without acromegaly are often prescribed multiple medications, the overall prevalence of concomitant medications is substantially higher in patients with diseases such as acromegaly, and it is uncommon for a patient receiving acromegaly treatment to be prescribed no additional medications.

Almost all medications, regardless of route of administration, were observed to be more frequently prescribed for patients with acromegaly. The one exception, lisinopril, is an oral medication used to treat cardiovascular disease. The high prevalence of cardiovascular disorders in patients with and without acromegaly likely accounts for the comparable usage of lisinopril in both cohorts. Notably, the majority of all concomitant medications were oral medications. Physicians should consider the types of ongoing medications for individual patients during treatment decision-making, as the most appropriate treatment option may need to be adjusted depending on the number and type of medications that a patient is already receiving. Challenges posed by the prescription of multiple oral medications include managing potential drug-drug interactions as well as abiding by any food restrictions [26, 27, 35]. For example, many of the oral medications used to treat thyroid disorders and bone diseases (prescribed to $35.4 \%$ and $2.7 \%$ of patients with acromegaly in our analysis, respectively), as well as certain drugs to treat diabetes, are commonly taken while fasting [36-38]. Patients taking levothyroxine or alendronate must also generally continue fasting for a period of time before taking any other drugs $[37,38]$, including those to treat acromegaly. Furthermore, proton-pump inhibitors, prescribed in oral form for $22.2 \%$ of patients with acromegaly in this study, alter the acidic environment of the stomach and thus can impact absorption of other oral medications [39, 40].

On the other hand, surveys and clinical trials have shown that some patients experience pain with injections, fear of injections, or injection-site reactions such as nodules or indurations, and may therefore prefer to take oral medications [41-43]. Additionally, IM injectable medications in particular may pose other potential risks and complications not evident with oral or SC routes of administration when administered alongside anticoagulants. The sub-analysis found that patients with acromegaly were more likely to be receiving anticoagulants and more likely to receive injectable concomitant medications than those without acromegaly. These injectable medications include both SC and IM injections (such as IM depot testosterone). Certain studies have suggested that SC injections are preferable to IM injections due to fewer side effects (such as injection-site pain), and may allow for lower doses [44]. Furthermore, United Kingdom (UK) guidelines recommend against the use of IM injections in patients receiving anticoagulation therapy due to the risk of developing hematomas and bleeding [45]; this risk is not present for SC injections. While limited data from UK guidelines suggest that IM injections may be used safely with newer oral anticoagulants such as dabigatran, rivaroxaban, edoxaban, or apixaban when administered 24 hours after previous anticoagulant dose [45], IM injections may not be a viable option for patients who are prescribed anticoagulants for daily use. Notably, the potential risk posed by IM injections for people receiving anticoagulants is not mentioned in US cardiology guidelines [46-48], which may in part explain the prevalence of IM injectable medications observed in the anticoagulation sub-analysis.

In order to alleviate the potential medication burden on patients and to encourage medication adherence, it is important to consider patient preference as well as the varying levels of risk or complications associated with different modes of administration when prescribing treatments for acromegaly. For instance, in cases where patients are already receiving a complex regimen of oral medications that requires fasting, it may be preferable to prescribe additional medications in injectable form wherever possible, while an oral or SC route of administration for additional medications may be preferred for patients treated with anticoagulants.

Clinical trials in acromegaly reported similar findings to this real-world analysis. In the PRIMARYS (NCT00690898) and LEAD (NCT00701363) open-label trials investigating lanreotide depot, patients with acromegaly generally experienced a high prevalence of comorbidities, and most patients were prescribed one or more concomitant medications [49]. While results from clinical trials are generally robust and well-controlled, data derived from claims databases cover more diverse patient populations and may provide a more accurate representation of patients in the real-world and their clinical management.

\section{Strengths}

To our knowledge, this study is the first to clearly define comorbidities associated with acromegaly compared with 
a control population without acromegaly, and to investigate a wide range of associated concomitant medications in a real-world setting. Previous studies have assessed concomitant medication use in patients with acromegaly, generally focusing on specific classes of medications [50]. The claims database used in this study is large, containing thousands of patients with acromegaly and up-to-date results spanning approximately the last decade. The availability of data for patients without acromegaly allowed for a matched control cohort for comparison with the acromegaly cohort. Finally, 1:5 matching reduced the standard error of the outcome variables in the control group, therefore strengthening the power of the between-group comparisons.

\section{Limitations}

This study analyzed data solely from the US; as such, generalization to other populations is limited. Since the results were obtained from an administrative claims database, missing data or coding errors were encountered, and it was not possible to verify actual rates of medication adherence. In addition, laboratory data to determine biochemical control of acromegaly, such as GH and IGF-1 levels, were not available. It should be noted that concomitant medication prescriptions were analyzed throughout the course of each patient's study period. While this method ensured that all prescriptions were counted, patients may have received different prescriptions at different times, and therefore may not have been taking all recorded medications at the same time. Furthermore, as this analysis sought to explore concomitant medication use in patients receiving medical therapy for acromegaly, patients in remission due to surgery or radiotherapy would not have been included. Nevertheless, patients with acromegaly were prescribed significantly more medications than patients without acromegaly over the course of the study. While analysis of concomitant medications evaluated all concomitant medications used in patients with acromegaly, the comorbidities analysis was limited to comorbidities known to be prevalent in patients with acromegaly. The CCI score helped mitigate this limitation by accounting for a broader array of comorbidities. It is also possible that patients with acromegaly are monitored more closely than patients without acromegaly, which could lead to over-reporting of comorbidities in the acromegaly cohort. As this was a descriptive study, no causal associations between patients with acromegaly and outcomes of interest could be determined using the real-world data. This study also included no adjustment for multiplicity/hypothesis generation.

\section{Conclusions}

This analysis highlighted the high prevalence of comorbidities and frequency of prescribed concomitant medications in patients with acromegaly. Patients with acromegaly had significantly more comorbidities than patients without acromegaly and were prescribed significantly more concomitant medications for all medication classes and almost all medication ingredients, including those taken in oral and injectable forms, and in forms other than oral or injectable. Most patients in the acromegaly cohort were prescribed $>3$ concomitant medications, and the number of comorbidities and number of prescribed concomitant medications were moderately positively correlated. Additionally, patients with acromegaly were more likely to be receiving anticoagulants and concomitant injectable medications (including IM injections) than patients without acromegaly. Use of real-word data enables the exploration of a heterogenous population beyond clinical trials, to gain insights into current medical practices and treatments. Physicians should consider the frequency and form of patients' existing concomitant medications when prescribing treatments for acromegaly, particularly given the availability of treatments with different methods of administration.

Supplementary Information The online version contains supplementary material available at https://doi.org/10.1007/s11102-021-01198-5.

Acknowledgements The authors acknowledge Aude Houchard, MPH, from Ipsen, for statistical advice, Kathryn Munoz, PhD, for contributions to study design, analysis, and interpretation of the data, and Isabel Haber, BS, and Oliver Palmer, BSc (Hons), from Costello Medical, for medical writing and editorial assistance based on the authors' input and direction on the detailed outline and manuscript. This study was funded by Ipsen.

Author contributions Substantial contributions to study conception and design: MF, AB, MdPS, YD, AdP, SP, SN, AROJR, SM; substantial contributions to analysis and interpretation of the data: MF, AB, MdPS, YD, AdP, SP, SN, AROJR, SM; drafting the article or revising it critically for important intellectual content: MF, AB, MdPS, YD, AdP, SP, SN, AROJR, SM; final approval of the version of the article to be published: MF, AB, MdPS, YD, AdP, SP, SN, AROJR, SM.

Funding This study was sponsored by Ipsen. Support for third-party writing assistance for this article was funded by Ipsen in accordance with Good Publication Practice (GPP3) guidelines (http://www.ismpp. org/gpp3).

Data availability Owing to the nature of this claims database analysis, Ipsen does not have access to individual participant data. The datasets analyzed in this study are available through the IBM® MarketScan ${ }^{\circledR}$ database. However, the authors cannot share the data with any third parties or make the data publicly available owing to protections around the sharing of private health data.

Code availability Not applicable. 


\section{Declarations}

Conflict of interest MF: Scientific Consultant for Chiasma, Crinetics, Ionis, Ipsen, Pfizer, and Recordati; Principal Investigator with support to the institution for Chiasma, Crinetics, Ionis, and Novartis; on the Editorial Board of Pituitary; AB: Editor for Pituitary; MdPS: employee of Ipsen; YD: employee of Ipsen; AdP: employee of Ipsen; SP: has been a speaker at workshops and/or Advisory Board Member for Crinetics, Ipsen, Novartis, Pfizer, Recordati, and Takeda; on the Editorial Board of Pituitary; SN: consulting and research fees from Ipsen and Pfizer; consulting fees from Crinetics and Recordati; on the Editorial Board of Pituitary; AROJR: employee of Ipsen; SM: consulting fee; Chiasma, Crinetics, Ionis, Ipsen; funding to institution from Pfizer; Editor-in-Chief for Pituitary.

Open Access This article is licensed under a Creative Commons Attribution 4.0 International License, which permits use, sharing, adaptation, distribution and reproduction in any medium or format, as long as you give appropriate credit to the original author(s) and the source, provide a link to the Creative Commons licence, and indicate if changes were made. The images or other third party material in this article are included in the article's Creative Commons licence, unless indicated otherwise in a credit line to the material. If material is not included in the article's Creative Commons licence and your intended use is not permitted by statutory regulation or exceeds the permitted use, you will need to obtain permission directly from the copyright holder. To view a copy of this licence, visit http://creativecommons.org/licenses/by/4.0/.

\section{References}

1. Fleseriu M, Barkan A, del Schneider MP, Darhi Y, de Pierrefeu A, Munoz K, Ribeiro-Oliveira A, Melmed S (2021) The pharmacological burden of comorbidities in acromegaly. J Endocr Soc 5(Suppl 1):A649-A650. https://doi.org/10.1210/jendso/bvab048. 1324

2. Katznelson L, Laws ER Jr, Melmed S, Molitch ME, Murad MH, Utz A, Wass JAH (2014) Acromegaly: an Endocrine Society clinical practice guideline. J Clin Endocrinol Metab 99(11):39333951. https://doi.org/10.1210/jc.2014-2700

3. Melmed S (2020) Pituitary-tumor endocrinopathies. N Engl J Med 382(10):937-950. https://doi.org/10.1056/NEJMra1810772

4. Melmed S, Bronstein MD, Chanson P, Klibanski A, Casanueva FF, Wass JAH, Strasburger CJ, Luger A, Clemmons DR, Giustina A (2018) A consensus statement on acromegaly therapeutic outcomes. Nat Rev Endocrinol 14(9):552-561. https://doi.org/10. 1038/s41574-018-0058-5

5. Vila G, Luger A, van der Lely AJ, Neggers S, Webb SM, Biller BMK, Valluri S, Hey-Hadavi J (2020) Hypertension in acromegaly in relationship to biochemical control and mortality: global ACROSTUDY outcomes. Front Endocrinol (Lausanne) 11:577173. https://doi.org/10.3389/fendo.2020.577173

6. Lavrentaki A, Paluzzi A, Wass JA, Karavitaki N (2017) Epidemiology of acromegaly: review of population studies. Pituitary 20(1):4-9. https://doi.org/10.1007/s11102-016-0754-x

7. AlDallal S (2018) Acromegaly: a challenging condition to diagnose. Int J Gen Med 11:337-343. https://doi.org/10.2147/ijgm. S169611

8. Brue T, Castinetti F (2016) The risks of overlooking the diagnosis of secreting pituitary adenomas. Orphanet J Rare Dis 11(1):135. https://doi.org/10.1186/s13023-016-0516-x

9. Martín-Rodríguez JF, Madrazo-Atutxa A, Venegas-Moreno E, Benito-López P, Gálvez MÁ, Cano DA, Tinahones FJ, Torres-Vela E, Soto-Moreno A, Leal-Cerro A (2013) Neurocognitive function in acromegaly after surgical resection of GH-secreting adenoma versus naïve acromegaly. PLoS ONE 8(4):e60041. https://doi.org/ 10.1371/journal.pone.0060041

10. Dekkers OM, Biermasz NR, Pereira AM, Romijn JA, Vandenbroucke JP (2008) Mortality in acromegaly: a metaanalysis. J Clin Endocrinol Metab 93(1):61-67. https://doi.org/10.1210/jc. 2007-1191

11. Colao A, Spinelli L, Marzullo P, Pivonello R, Petretta M, Di Somma C, Vitale G, Bonaduce D, Lombardi G (2003) High prevalence of cardiac valve disease in acromegaly: an observational, analytical, case-control study. J Clin Endocrinol Metab 88(7):3196-3201. https://doi.org/10.1210/jc.2002-021099

12. Melmed S (2009) Acromegaly pathogenesis and treatment. J Clin Investig 119(11):3189-3202. https://doi.org/10.1172/jci39375

13. Gadelha MR, Kasuki L, Lim DST, Fleseriu M (2019) Systemic complications of acromegaly and the impact of the current treatment landscape: an update. Endocr Rev 40(1):268-332. https:// doi.org/10.1210/er.2018-00115

14. Matta MP, Couture E, Cazals L, Vezzosi D, Bennet A, Caron P (2008) Impaired quality of life of patients with acromegaly: control of GH/IGF-I excess improves psychological subscale appearance. Eur J Endocrinol 158(3):305-310. https://doi.org/10.1530/ eje-07-0697

15. Giustina A, Barkan A, Beckers A, Biermasz N, Biller BMK, Boguszewski C, Bolanowski M, Bonert V, Bronstein MD, Casanueva FF, Clemmons D, Colao A, Ferone D, Fleseriu M, Frara S, Gadelha MR, Ghigo E, Gurnell M, Heaney AP, Ho K, Ioachimescu A, Katznelson L, Kelestimur F, Kopchick J, Krsek M, Lamberts S, Losa M, Luger A, Maffei P, Marazuela M, Mazziotti G, Mercado M, Mortini P, Neggers S, Pereira AM, Petersenn S, Puig-Domingo M, Salvatori R, Shimon I, Strasburger C, Tsagarakis S, van der Lely AJ, Wass J, Zatelli MC, Melmed S (2020) A consensus on the diagnosis and treatment of acromegaly comorbidities: an update. J Clin Endocrinol Metab. https://doi.org/10. 1210/clinem/dgz096

16. McCabe J, Ayuk J, Sherlock M (2016) Treatment factors that influence mortality in acromegaly. Neuroendocrinology 103(1):66-74. https://doi.org/10.1159/000375163

17. Whittington M, Munoz K, Whalen J, Ribeiro-Oliveira A Jr, Campbell J (2021) Economic and clinical burden of comorbidities among patients with acromegaly. Growth Horm IGF Res 59:101389. https://doi.org/10.1016/j.ghir.2021.101389

18. Fleseriu M, Biller BMK, Freda PU, Gadelha MR, Giustina A, Katznelson L, Molitch ME, Samson SL, Strasburger CJ, van der Lely AJ, Melmed S (2021) A Pituitary Society update to acromegaly management guidelines. Pituitary 24(1):1-13. https://doi. org/10.1007/s11102-020-01091-7

19. Burton T, Le Nestour E, Bancroft T, Neary M (2013) Real-world comorbidities and treatment patterns of patients with acromegaly in two large US health plan databases. Pituitary 16(3):354-362. https://doi.org/10.1007/s11102-012-0432-6

20. Maia B, Kasuki L, Gadelha MR (2020) Novel therapies for acromegaly. Endocr Connect 9(12):R274-R285. https://doi.org/10. 1530/EC-20-0433

21. Sabbatini M, Garofalo G, Borrelli S, Vitale S, Torino M, Capone D, Russo L, Pisani A, Carrano R, Gallo R, Federico S (2014) Efficacy of a reduced pill burden on therapeutic adherence to calcineurin inhibitors in renal transplant recipients: an observational study. Patient Prefer Adherence 8:73-81. https://doi.org/10.2147/ ppa.s54922

22. Blüher M, Kurz I, Dannenmaier S, Dworak M (2015) Pill burden in patients with type 2 diabetes in Germany: subanalysis from the prospective, noninterventional PROVIL study. Clin Diabetes 33(2):55. https://doi.org/10.2337/diaclin.33.2.55

23. Farrell B, French Merkley V, Ingar N (2013) Reducing pill burden and helping with medication awareness to improve adherence. Can 
Pharm J 146(5):262-269. https://doi.org/10.1177/1715163513 500208

24. Mohammed MA, Moles RJ, Chen TF (2016) Medication-related burden and patients' lived experience with medicine: a systematic review and metasynthesis of qualitative studies. BMJ Open 6(2):e010035. https://doi.org/10.1136/bmjopen-2015-010035

25. van Merode T, van de Ven K, van den Akker M (2018) Patients with multimorbidity and their treatment burden in different daily life domains: a qualitative study in primary care in the Netherlands and Belgium. J Comorbidity 8(1):9-15. https://doi.org/10. 15256/joc.2018.8.119

26. Khandeparkar A, Rataboli PV (2017) A study of harmful drugdrug interactions due to polypharmacy in hospitalized patients in Goa Medical College. Perspect Clin Res 8(4):180-186. https:// doi.org/10.4103/picr.PICR_132_16

27. Marzolini C, Elzi L, Gibbons S, Weber R, Fux C, Furrer H, Chave J-P, Cavassini M, Bernasconi E, Calmy A (2010) Prevalence of comedications and effect of potential drug-drug interactions in the Swiss HIV Cohort Study. Antivir Ther 15(3):413. https://doi. org/10.3851/imp1540

28. Homayun B, Lin X, Choi H-J (2019) Challenges and recent progress in oral drug delivery systems for biopharmaceuticals. Pharmaceutics 11(3):129. https://doi.org/10.3390/pharmaceutics11 030129

29. Kim H, Park H, Lee SJ (2017) Effective method for drug injection into subcutaneous tissue. Sci Rep 7(1):9613-9613. https://doi.org/ 10.1038/s41598-017-10110-w

30. Quan H, Li B, Couris CM, Fushimi K, Graham P, Hider P, Januel JM, Sundararajan V (2011) Updating and validating the Charlson comorbidity index and score for risk adjustment in hospital discharge abstracts using data from 6 countries. Am J Epidemiol 173(6):676-682. https://doi.org/10.1093/aje/kwq433

31. Python Software Foundation (n.d.) Python language reference. http://www.python.org. Accessed 7 Dec 2021

32. Kamusheva M, Vandeva S, Mitov K, Rusenova Y, Elenkova A, Zacharieva S, Mitkova Z, Tachkov K, Dimitrova M, Doneva M, Tcharaktchiev D, Petrova G (2020) New epidemiological, clinical and economic data for patients with acromegaly in Bulgaria. Front Public Health 8:147. https://doi.org/10.3389/fpubh.2020.00147

33. Petrossians P, Daly AF, Natchev E, Maione L, Blijdorp K, Sahnoun-Fathallah M, Auriemma R, Diallo AM, Hulting A-L, Ferone D, Hana V Jr, Filipponi S, Sievers C, Nogueira C, FajardoMontañana C, Carvalho D, Hana V, Stalla GK, Jaffrain-Réa M-L, Delemer B, Colao A, Brue T, Neggers SJCMM, Zacharieva S, Chanson P, Beckers A (2017) Acromegaly at diagnosis in 3173 patients from the Liège Acromegaly Survey (LAS) Database. Endocr Relat Cancer 24(10):505-518. https://doi.org/10.1530/ ERC-17-0253

34. Kantor ED, Rehm CD, Haas JS, Chan AT, Giovannucci EL (2015) Trends in prescription drug use among adults in the United States From 1999-2012. JAMA 314(17):1818-1831. https://doi.org/10. 1001/jama.2015.13766

35. Bushra R, Aslam N, Khan AY (2011) Food-drug interactions. Oman Med J 26(2):77-83. https://doi.org/10.5001/omj.2011.21

36. FDA (2008) Prescribing information: glucotrol—glipzide tablet. FDA. https://www.accessdata.fda.gov/drugsatfda_docs/label/ 2008/017783s019lbl.pdf. Accessed 7 Dec 2021

37. Colucci P, Yue CS, Ducharme M, Benvenga S (2013) A review of the pharmacokinetics of levothyroxine for the treatment of hypothyroidism. Eur Endocrinol 9(1):40-47. https://doi.org/10.17925/ EE.2013.09.01.40

38. Wiesner A, Szuta M, Galanty A, Paśko P (2021) Optimal dosing regimen of osteoporosis drugs in relation to food intake as the key for the enhancement of the treatment effectiveness-a concise literature review. Foods (Basel Switz) 10(4):720. https://doi.org/ 10.3390/foods 10040720
39. Wedemeyer R-S, Blume H (2014) Pharmacokinetic drug interaction profiles of proton pump inhibitors: an update. Drug Saf 37(4):201-211. https://doi.org/10.1007/s40264-014-0144-0

40. FDA (2020) Highlights of prescribing information. In: MYCAPSSA (octreotide) delayed-release capsules, for oral use. FDA. https://www.accessdata.fda.gov/drugsatfda_docs/label/ 2020/208232s000lbl.pdf. Accessed 7 Dec 2021

41. Geer EB, Sisco J, Adelman DT, Ludlam WH, Haviv A, Liu S, Mathias SD, Gelbaum D, Shi L (2020) Patient reported outcome data from acromegaly patients treated with injectable somatostatin receptor ligands (SRLs) in routine clinical practice. BMC Endocr Disord 20(1):117. https://doi.org/10.1186/s12902-020-00595-4

42. Fleseriu M, Fogelfeld L, Gordon MB, Sisco J, Crosby RD, Ludlam WH, Haviv A, Mathias SD (2020) An evaluation of the Acromegaly Treatment Satisfaction Questionnaire (Acro-TSQ) in adult patients with acromegaly, including correlations with other patient-reported outcome measures: data from two large multicenter international studies. Pituitary 23(4):347-358. https://doi. org/10.1007/s11102-020-01038-y

43. Caron P, Cogne M, Raingeard I, Bex-Bachellerie V, Kuhn JM (2006) Effectiveness and tolerability of 3-year lanreotide Autogel treatment in patients with acromegaly. Clin Endocrinol (Oxf) 64(2):209-214. https://doi.org/10.1111/j.1365-2265.2006.02450.x

44. Spratt DI, Stewart II, Savage C, Craig W, Spack NP, Chandler DW, Spratt LV, Eimicke T, Olshan JS (2017) Subcutaneous injection of testosterone is an effective and preferred alternative to intramuscular injection: demonstration in female-to-male transgender patients. J Clin Endocrinol Metab 102(7):2349-2355. https://doi. org/10.1210/jc.2017-00359

45. NHS (2018) Can small volume intramuscular injections be given to patients taking oral anticoagulants? NHS. https://www.sps.nhs. uk/wp-content/uploads/2018/09/UKMI_QA_IM-inj-anticoag_ partial-update_Sept2018.pdf. Accessed 7 Dec 2021

46. Hirsh J, Fuster V, Ansell J, Halperin JL (2003) American Heart Association/American College of Cardiology Foundation guide to warfarin therapy. Circulation 107(12):1692-1711. https://doi. org/10.1161/01.CIR.0000063575.17904.4E

47. Alpert JS (2019) Take-home messages from the recently updated AHA/ACC guidelines for atrial fibrillation. Am J Med 132(12):1363-1364. https://doi.org/10.1016/j.amjmed.2019.07. 021

48. Kumbhani DJ, Cannon CP, Beavers CJ, Bhatt DL, Cuker A, Gluckman TJ, Marine JE, Mehran R, Messe SR, Patel NS, Peterson BE, Rosenfield K, Spinler SA, Thourani VH (2021) 2020 ACC Expert consensus decision pathway for anticoagulant and antiplatelet therapy in patients with atrial fibrillation or venous thromboembolism undergoing percutaneous coronary intervention or with atherosclerotic cardiovascular disease. J Am Coll Cardiol 77(5):629-658. https://doi.org/10.1016/j.jacc.2020.09.011

49. Petersenn S, Houchard A, del Pilar Schneider M, Ribeiro-Oliveira A Jr, Neggers S (2021) Use of oral concomitant medications in patients with acromegaly. J Endocr Soc 5(Suppl 1):A528-A529. https://doi.org/10.1210/jendso/bvab048.1076

50. Brue T, Lindberg A, van der Lely JA, Akerblad AC, KoltowskaHäggström M, Gomez R, Droste M, Hey-Hadavi J, Strasburger CJ, Camacho-Hübner C (2019) Diabetes in patients with acromegaly treated with pegvisomant: observations from ACROSTUDY. Endocrine 63(3):563-572. https://doi.org/10.1007/ s12020-018-1792-0

Publisher's Note Springer Nature remains neutral with regard to jurisdictional claims in published maps and institutional affiliations. 